\title{
Evaluation of Efficacy of Customized Lidocaine Bioadhesive Anaesthetic Patch for Extraction of Primary Tooth - An Invitro Study
}

\author{
Amith Adyanthaya ${ }^{1}$, Risana K.․․ Aparna Sivaraman ${ }^{3}$, Gopika Gopan A. ${ }^{4}$, \\ Nazreen Ayub K. ${ }^{5}$, Reshma Aloysious ${ }^{6}$, Sangeetha C.R.. ${ }^{7}$ Swetha S. Nair ${ }^{8}$ \\ 1, 2, 3, 4, 5, 6, 7, 8 Department of Preventive and Paediatric Dentistry, \\ KMCT Dental College, Mukkam, Calicut, Kerala, India.
}

\section{ABSTRACT}

\section{BACKGROUND}

We wanted to clinically evaluate the efficacy of lidocaine bioadhesive patches for extraction in paediatric dentistry and assess the comfort and pain response by sound eye motor (SEM) scale and intensity of pain using the visual analogue scale (VAS).

\section{METHODS}

A total of thirty-five co-operative children of age group 8 - 12 years without systemic diseases who needed dental extraction participated in the study. Extraction was carried out using customized lidocaine bioadhesive patches as anaesthetic agent. Evaluation of comfort and pain response was done by sound eye motor scale and intensity of pain using the visual analogue scale. Statistical analysis was done with SPSS version 2.0. Comparison of SEM scale and VAS scores between different subgroups was done using a chi-square test. P value less than 0.001 was considered statistically significant.

\section{RESULTS}

Children of higher age groups belonging to both the genders demonstrated less perception to pain during extractions using lidocaine patch. During extraction of firm teeth and teeth with Grade I mobility, perception of pain was more in girls. Maxillary arch extraction in children with various grades of mobility perceived less pain. Irrespective of age, gender and arches, teeth with Grade II and Grade III mobility were extracted with minimal VAS and SEM score.

\section{CONCLUSIONS}

Bioadhesive patches serve as a potential non-invasive alternative to traditional modes of local anaesthetic delivery with the advantage of eliminating needle phobia and possible negative influence on the behaviour.

\section{KEY WORDS}

Bioadhesive Patches, Lidocaine, Extraction, Paediatric Dentistry
Corresponding Author:

Dr. Risana K.

KMCT Dental College

Mukkam, Calicut, Kerala, India.

E-mail: risanarahoof@gmail.com

DOI: $10.14260 / j e m d s / 2021 / 378$

How to Cite This Article:

Adyanthaya A, Risana K, Sivaraman A. et al. Evaluation of efficacy of customized lidocaine bioadhesive anaesthetic patch for extraction of primary tooth - an invitro study. J Evolution Med Dent Sci 2021;10(24):1830-1834, DOI: 10.14260/jemds/2021/378

Submission 09-01-2021,

Peer Review 16-04-2021,

Acceptance 23-04-2021,

Published 14-06-2021.

Copyright (C) 2021 Amith Adyanthaya et al. This is an open access article distributed under Creative Commons Attribution License [Attribution 4.0 International (CC BY 4.0)] 


\section{BACKGROUND}

Pain and dentistry are often synonymous in the mind of patients. Patients perceive a good dentist as a practitioner who causes little or no discomfort. Meanwhile, dental practitioners identify a good anaesthetic as one that allows them to focus on operative procedures without distractions from pain-induced patient movements. The everyday practice of dentistry is therefore based upon achieving adequate local anaesthesia. Research has shown that the fear of pain related with dentistry is closely associated with the most common method for blocking pain during dental procedures, i.e., intraoral administration of local anaesthetics. This is considered aversive due to the pain associated with the injection and the perceived threat of needle puncture prior to the injection. ${ }^{1}$ Surveys found that individuals who reported themselves as highly anxious of dental treatment were worried about receiving oral injections and demonstrated an association between high dental anxieties and missed or delayed appointments. $^{2}$ According to the American Academy of paediatric dentistry, prevention of pain during dental procedures can nurture the relationship of the patient and the dentist, building trust, allaying fear and anxiety, and promoting a positive dental attitude. ${ }^{3}$ Children most often associate pain during a dental visit with the administration of local anaesthetics. ${ }^{4}$ Studies have shown that feel of the injection needle penetrating the mucosa is the most fear provoking stimuli for children, the sight of the needle being the second. ${ }^{5}$ The dentist must possess certain knowledge, readiness, and skill for the administration of painless anaesthesia. There are two important aspects in this context; the first is behaviour modification through apt communication and the second is a technical procedure in order to ensure a non-traumatic experience for the child.

Topical anaesthesia is widely used in dental procedures and is a fundamental part of local anaesthetic administration as it has both psychological and pharmacological impact. Topical anaesthetics control pain perception and hence, alter the reaction to pain by blocking the transmission of signals from the terminal fibres of the sensory nerves. However, most commercially available medications are in the form of liquid or semisolid, which cannot provide prolonged effects intraorally. Their effects are limited to the control of painful stimuli occurring on or just beneath the mucosa. Although the intensity of anaesthesia is weak, topical anaesthetics have little side effects with easy administration and reduces pain caused by needle injections and can thus generate positive response towards dental treatment in patients. The application of topical anaesthetic can reduce the discomfort of intraoral anaesthetic injections; provides anaesthesia for intraoral operative procedures, provides symptomatic relief of pain due to superficial mucosal lesions such as ulcers or even relieves post extraction pain. Newer methods for delivery of local anaesthetics is an area of research in dentistry. There are ongoing efforts to develop various forms of topical anaesthetics with more potent effects in order to facilitate the provision of quality care by dentists, upon a thorough understanding of the products. The effect of topical anaesthetics is limited to the control of painful stimuli occurring on or just beneath the mucosa. ${ }^{6}$ In case of less invasive procedures it can eliminate the need for injection as this system provides pain relief to the bone.

\section{Objectives}

To clinically evaluate the efficacy of lidocaine bioadhesive patches for extraction procedures in Paediatric dentistry and assess the comfort and pain response by sound eye motor (SEM) scale and intensity of pain using visual analogue scale.

\section{METHODS}

This is an in vitro experimental study done in the Department of Paediatric and Preventive Dentistry, KMCT dental college, Mukkam, Calicut, Kerala from 25 November 2019 to 13 January 2020. A total of thirty-five patients who reported for extraction in the Department of Pedodontics was included in the study. Sample size was estimated based on previous studies. The minimum required sample size was calculated to be 35 to be sufficient to detect effective size of 0.15 a power of 0.85 and a significance level of $5 \%$. Ethical clearance was obtained from the institutional ethical committee. The procedure was explained verbally both to the parent as well as the patient. Written informed consent was obtained from parents of the participants included in the study.

\section{Inclusion Criteria}

Children of age 8 - 12 years with a rating of 3 (positive) and 4 (definitely positive) on Frankl's behaviour rating scale were included.7 Minimum patient ability in terms of visual ability and hand-eye coordination was required in VAS.7,8 The ability of the participants to complete VAS was assessed before including in the study.

\section{Exclusion Criteria}

Children who were uncooperative and with any systemic diseases and known hypersensitivity to lidocaine or other local anaesthetic agents were excluded.

\section{Preparation of Lidocaine Bioadhesive Patches}

Raw materials used for the preparation of bioadhesive patch were Hydroxypropyl methylcellulose, ethanol, and Dimethyl sulfoxide. Preparation of the bioadhesive patch was done using the solvent casting method. 1 gm of Hydroxypropyl methylcellulose was added to $4 \mathrm{ml}$ of ethanol and kept aside for hydration of polymer. After an hour, Hydroxypropyl methylcellulose particles appeared completely wet with no granules. Following this $600 \mathrm{mg}$ of lidocaine dissolved in $4 \mathrm{ml}$ ethanol was added and stirred until a clear solution was obtained. $0.1 \mathrm{ml}$ of Dimethyl sulfoxide was added to the polymer solution to enhance the permeation capacity. The solution was poured into prepared glass moulds of dimension $5 \mathrm{~cm} * 3 \mathrm{~cm}$ lined with an aluminium foil to serve as a backing film. The solvent was allowed to evaporate for a period of 24 hours at room temperature. Dried films were cut into pieces of dimensions $2 \mathrm{~cm} * 0.5 \mathrm{~cm} \mathrm{(} 1 \mathrm{~cm}^{2}$ surface area) and were placed in a desiccator containing silica gel to avoid desiccation and drying of the patches. (Figure 1) 


\begin{tabular}{|c|c|c|c|c|c|c|c|c|c|c|c|}
\hline & \multirow[t]{2}{*}{ Value } & \multicolumn{2}{|c|}{ Age in Years } & \multicolumn{2}{|c|}{ Site } & \multicolumn{2}{|c|}{ Gender } & \multicolumn{4}{|c|}{ Grades of Mobility } \\
\hline \multirow{3}{*}{ VAS } & & $8-10$ & $10-12$ & Maxilla & Mandible & Boys & Girls & Firm & Grade 1 & Grade 2 & Grade 3 \\
\hline & Range & $3-8$ & $1-4$ & $1-4^{*}$ & $3-8$ & $1-6$ & $2-8$ & \multirow{2}{*}{$4-8$} & \multirow{2}{*}{$4-5$} & \multirow{2}{*}{$1-4$} & \multirow{2}{*}{$1-3$} \\
\hline & Mean \pm SD & $4.8 \pm 0.94$ & $3.15 \pm 0.59$ & $2.2 \pm 0.55$ & $3.2 \pm 0.94$ & $2.8 \pm 0.95$ & $3.47 \pm 0.48$ & & & & \\
\hline & Range & $3-7$ & $2-4$ & $3-5$ & $3-7$ & $2-5$ & $3-7$ & \multirow{2}{*}{$5-7$} & \multirow{2}{*}{$3-6$} & \multirow{2}{*}{3} & \multirow{2}{*}{$2-3$} \\
\hline SEM & Mean \pm SD & $4.1 \pm 0.8$ & $3.9 \pm 0.49$ & $3.23 \pm 0.46$ & $3.8 \pm 0.79$ & $3.7 \pm 0.48$ & $3.76 \pm 0.86$ & & & & \\
\hline
\end{tabular}

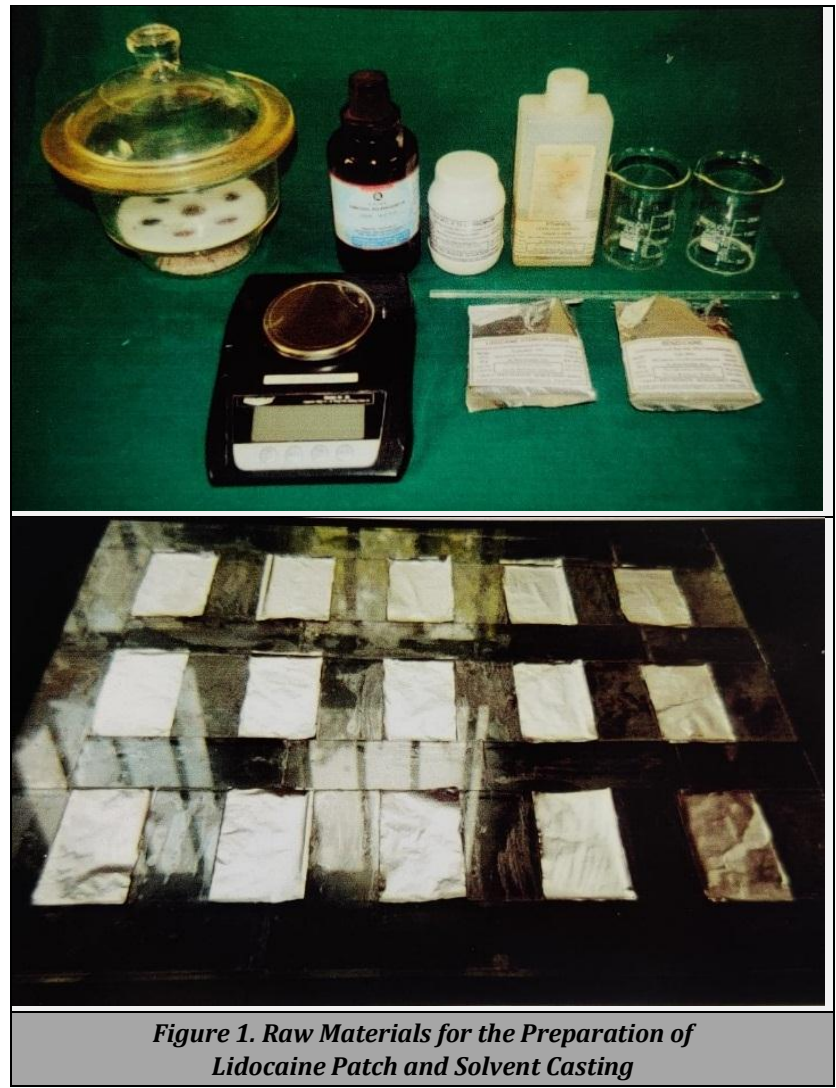

Procedure of Extraction Using Lidocaine Patches

Lidocaine patches were placed both buccal and lingual to the tooth to be extracted with firm finger pressure for 10 seconds. The patch was retained at the site for $5 \mathrm{~min}$. Anaesthetic effect was evaluated using a periosteal elevator before extraction and the patch was retained at the site till completion of the procedure. The site of placement of the patch was examined for ulcerations or hypersensitivity reactions immediately and 24 hours post extraction. (Figure 2)

\section{Evaluation of the Pain Response}

Evaluation of the pain response was done using both subjective and objective scales. Subjective evaluation was done with a visual analogue scale (Figure 3). A brief explanation was given to the participant about the scale and the child was asked to choose a score that best described his / her intensity of perceived pain during the extraction.

For objective pain response evaluation sound eye motor scale was used. ${ }^{9}$ (Figure 4) Each subject was observed during the extraction procedure and changes in sound, eye movements, and motor movements were calibrated. 2 independent blinded observers were assigned for scoring, and the mean score was taken.

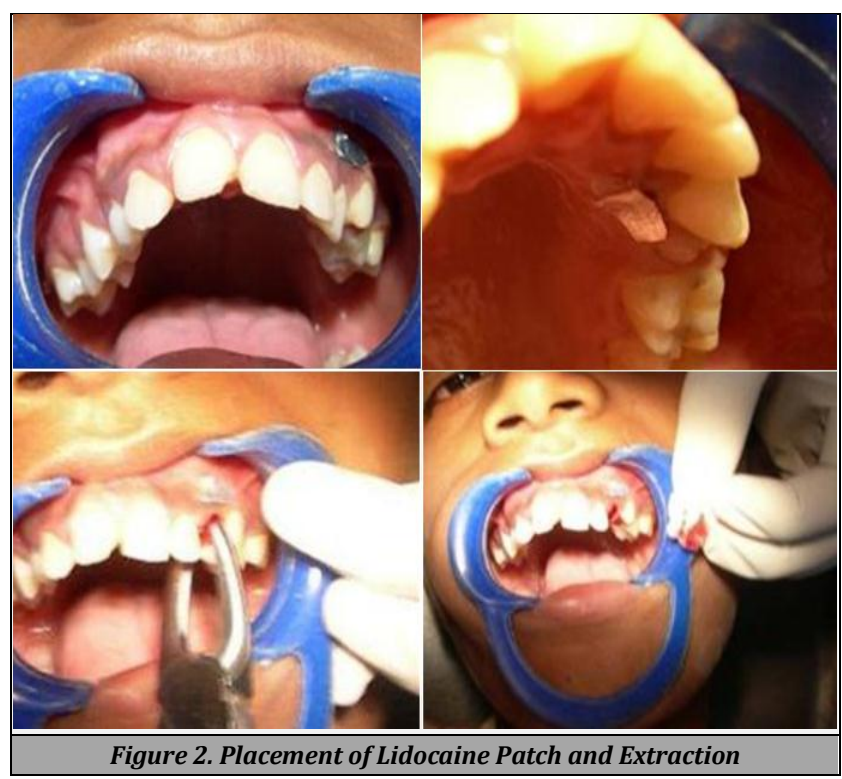

\section{Statistical Analysis}

Statistical analysis was done with SPSS version 2.0. Comparison of sound eye motor scale and visual analogue scale scores between different subgroups was done using chi square test. A value of less than 0.05 was considered statistically significant.

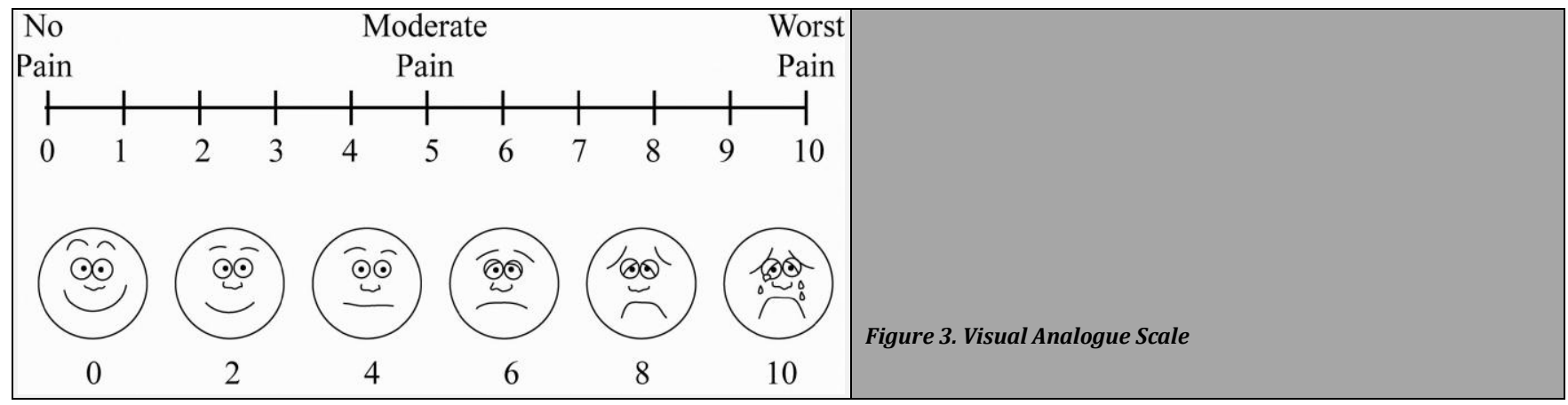




\begin{tabular}{|c|c|c|c|c|}
\hline Sound & $\begin{array}{l}\text { No Sounds } \\
\text { indicating pain }\end{array}$ & $\begin{array}{l}\text { Non Specific Sounds which may } \\
\text { indicate pain. }\end{array}$ & $\begin{array}{l}\text { Specific Verbal Complaints } \\
\text { raising voice. }\end{array}$ & $\begin{array}{l}\text { Verbal complaints } \\
\text { indicating intense pain. }\end{array}$ \\
\hline . & $\begin{array}{l}\text { No ocular signs of } \\
\text { Pain } \\
\text { - Relaxed hands } \\
\text { - Body } \\
\text { apparently relaxed }\end{array}$ & $\begin{array}{l}\text { - Eyes wide open. } \\
\text { - Shows concern. } \\
\text { - No tears. } \\
\text { - Hands show stress or tension. } \\
\text { - Grasps hold of chair. } \\
\text { - Muscular tension. }\end{array}$ & $\begin{array}{l}\text { - Watery eyes. } \\
\text { - Blinking eyes. } \\
\text { - Arm or body movements } \\
\text { with no aggressive intention } \\
\text { - Physical contact. } \\
\text { - Pulling faces or grimacing }\end{array}$ & $\begin{array}{l}\text { - Crying } \\
\text { - Tears rolling } \\
\text { down the face. } \\
\text { Hand movement for } \\
\text { aggressive contact. }\end{array}$ \\
\hline $\boldsymbol{\theta}$ & & 3 & 4 & 5 \\
\hline & & Figure 4. Sound Eye Motor Scal & & \\
\hline
\end{tabular}

\section{RESULTS}

\section{Distribution of Samples}

The total 35 participants included in the study were divided into 2 groups according to age. Group 1 included participants of age 8 - 10 years and group 2 included participants of age 10 - 12 years. There were 15 participants in group 1 and 20 participants in group 2 . The total sample included 18 boys and 17 girls. In the total sample, 15 participants had extraction carried out in maxillary arch and 20 participants had extraction of mandibular teeth. The number of teeth which were firm, grade 1 , grade 2 , grade 3 mobility was $6,6,10$, and 13 respectively. Higher age group children perceived less pain subjectively and objectively during extraction procedures. Statistically significant less pain was perceived for maxillary arch extractions irrespective of age, gender, and different grades of mobility. Minimal subjective and objective pain perception was reported in the extraction of tooth with grade 2 and grade 3 mobility.

\section{Correlation between VAS and SEM}

Correlation between subjective pain response (VAS) and objective pain response (SEM scale) showed a significant and a similar relation considering different variants like age, gender, site and mobility.

\section{DISCUSSION}

With every passing day, new methods are being introduced to facilitate dental procedures, but the administration of local anaesthetic is still necessary for pain control during several dental procedures. The thought and performance of local anaesthetic injection often provoke feelings of discomfort for the patient. Therefore, any procedure that significantly reduces the unpleasantness of dental injection could serve as a positive reinforcement towards obtaining dental care.

Topical anaesthetics are frequently used in dentistry to reduce or eliminate pain during an injection procedure. The product would block the injection pain and in case of less invasive procedures, actually eliminate the need for an injection at all as this system can also provide pain relief to the bone. The topical anaesthetics that are frequently used are sprays, gels, and ointments and they lack bio adhesiveness to the oral mucosa, making them relatively ineffective. Moreover, the increased salivation because of the unpleasant taste of topical agents can cause washing off and thereby further reducing the duration of mucosal contact. The time span of contact of the anaesthetic agent with oral mucosa is a major factor that determines the duration and depth of anaesthesia. Routinely available topical anaesthetic agents were unable to attend the desired level of anaesthesia to perform minor procedures. Hence, bioadhesive system was used to overcome this problem and ensure contact with the oral mucosa for a prolonged duration. Bio adhesion is defined as the state in which two bodies, one or both of the adherents are biological and are held together for extended periods by interfacial forces. ${ }^{6}$ Topically applied patches have the advantages of better patient compliance, localized effect of the patch and elimination of any complications related to nerve injury on injection. These patches however have several disadvantages related to poor bioadhesion, greater expense, and longer application time. ${ }^{10}$ Overcoming all these disadvantages a new bioadhesive patch was formulated that was cost - effective, had a shorter application time, and good adhesive properties. ${ }^{11}$ Several studies have been done using a transoral delivery system called dentipatch containing $46.1 \mathrm{mg}$ of lidocaine. The concentration of the custom-made patches used in this study was $40 \mathrm{mg}$ per piece of dimension $2 \mathrm{~cm}^{*} 0.5 \mathrm{~cm}\left(1 \mathrm{~cm}^{2}\right.$ surface area). According to Houp et al. the onset of anaesthesia is within 5 min of application, and peak anaesthetic effects occur at 15 minutes.

The present study consisted of 35 children with an age range from 8 to 12 years. This age was selected to ensure the 
ability of child to do the scoring on VAS. Also, children of this age range would possess sufficient verbal skills to communicate well and understand the instructions and explanation given about the treatment. It is clinically important to note that uncooperative children can give inaccurate pain assessment, but all the children selected for this study were cooperative (positive or definitely positive according to Frankl's Behaviour rating scale). Since, pain is extremely difficult to quantify in children, two different scales (subjective and objective) were used to assess pain.

The SEM scale used is an objective study that measures pain or discomfort taking into account the SEM components of a child's response to stimulation. Moreover, this scale has a 90 $\%$ inter-rater reliability. The subjective scale used was VAS scale which measures the degree of unpleasantness or affective dimension of a child's pain experience especially in the children aged from 3 to 17 years. In the study, perception of pain was less in children of the higher age group. This was in accordance to a study done by Khatri Amit et al. and Woodrow et al. who suggested that as age increases tolerance to cutaneous pain increases and visible anxious and uncooperative behaviour would be exhibited more by younger children as elder children would have better coping strategies.11,12 The increased pain perception reported by girls was in accordance to the findings by Lu q Tsao et al. The difference is attributed to the female children having tendency of seeking emotional support and are more likely to exhibit lower pain tolerance and have a habitual behaviour of more intense pain expression. ${ }^{13}$

In the present study, children were more comfortable for extraction in the maxillary arch. The difference is attributed to the histological bone pattern of the maxilla which is more porous and cancellous which will aid in better diffusion of the drug. ${ }^{14}$ This positive effect towards reducing pain could be attributed to the dimensions of the patch which facilitated better adaptation allowing perfect bio adhesiveness and better diffusion thereby providing sufficient anaesthetic effect. The higher salivary flow in the mandible than in the maxilla might also cause dislodgement of the patch from the site of placement. Minimal perception of pain during the extraction of tooth with grade 2 and $3^{15}$ mobility could be possibly due to the depth of anaesthesia attained being sufficient to anaesthetise the partly degenerated nerve fibres before physiologic shedding of the deciduous tooth. Children's rating of their pain was directly related to the scores recorded by the observer thereby strengthening the validity of the scales utilized to assess the observed pain and the self - reported pain. This was described by Soad et al. ${ }^{16}$

\section{CONCLUSIONS}

Lidocaine containing bioadhesive patches can be used as a sole anaesthetic agent in extraction procedures in paediatric dentistry with higher efficacy in maxillary dental arch and tooth with grade 2 and grade 3 mobility. Higher age group children and boys are better candidates when considering the use of bioadhesive patches as an anaesthetic agent. In general, the lidocaine bioadhesive system proved to be able to produce anaesthesia to tissues which makes it possible to perform minor procedures using it as the sole anaesthetic agent. However, further studies are needed to evaluate the effect of increased application time and the systemic blood levels achieved by lidocaine patches.

Data sharing statement provided by the authors is available with the full text of this article at jemds.com.

Financial or other competing interests: None.

Disclosure forms provided by the authors are available with the full text of this article at jemds.com.

\section{REFERENCES}

[1] Rosenberg ES. A computer-controlled anesthetic delivery system in a periodontal practice: patient satisfaction and acceptance. J Esthet Restor Dent 2002;14(1):39-46.

[2] Robinson PD, Pitt Ford TR, McDonald F. Local anesthesia in dentistry. London: Reed Educational and Professional Publishing 2000.

[3] Guideline on use of local anesthesia for pediatric dental patients. Clinical Guidelines, Reference Manual. American Academy of Pediatric Dentistry 2009;32(6):10-11.

[4] Leopold A, Wilson S, Weaver JS, et al. Pharmacokinetics of lidocaine delivered from a transmucosal patch in children. Anesth Prog 2002;49(3):82-7.

[5] Ram D, Peretz B. Administering local anaesthesia to paediatric dental patients--current status and prospects for the future. Int J Paediatr Dent 2002;12(2):80-9.

[6] Good WR. Transdermal nitro-controlled delivery of nitroglycerin via the transdermal route. Drug Dev Ind Pharm 1983;9(4):647-70.

[7] Frankl SN, Shiere FR, Fogels HR. Should the parent remain with the child in the dental operatory? J Dent Child 1962;29:150-63.

[8] Flynn D, Van Schaik P, Van Wersch A. A comparison of multi-item likert and visual analogue scales for the assessment of transactionally defined coping. Eur J Psychol Assess 2004;20(1):49-58.

[9] Wright GZ, Weinberger SJ, Marti R, et al. The effectiveness of infiltration anaesthesia in the mandibular primary molar region. Pediatr Dent 1991;13(5):278-83.

[10] Shaikh R, Singh TRR, Garland MJ, et al. Mucoadhesive drug delivery systems. J Pharm Bioallied Sci 2011;3(1):89-100.

[11] Shergold OA, Fleck NA, King TS. The penetration of a soft solid by a liquid jet, with application to the administration of a needle-free injection. J Biomech 2006;39(14):2593602.

[12] Woodrow KM, Friedman GD, Siegelaub AB, et al. Pain tolerance: differences according to age, sex and race. Psychosom Med 1972;34(6):548-56.

[13] Lu Q, Tsao JC, Myers CD, et al. Coping predictors of children's laboratory-induced pain tolerance, intensity and unpleasantness. J Pain 2007;8(9):708-17.

[14] Malamed SF. Local anesthetic considerations in dental specialties. In: Handbook of Local Anesthesia. $5^{\text {th }}$ edn. St. Louis, Mo: Mosby 2004: p. 269, 274-275.

[15] Marya CM. Fental indices. A text book of public health dentistry. $1^{\text {st }}$ edn. London: Jaypee Brothers Medical Publishers 2011: p. 203.

[16] Abdelmoniem SA, Mahmoud SA. Comparative evaluation of passive, active and passive-active distraction techniques on pain perception during local anesthesia administration in children. J Adv Res 2016;7(3):551-6. 